\title{
Utility of the Diamond-Forrester classification in stratifying acute chest pain in an academic chest pain center
}

\author{
Robert Hamburger, DO, MPH, \\ University of Florida College of Medicine \\ John Spertus, MD, MPH, and \\ Saint Luke's Mid America Heart Institute/University of Missouri-Kansas City School of Medicine \\ David E. Winchester, MD \\ University of Florida College of Medicine
}

\begin{abstract}
Background-Because the Diamond-Forrester (DF) model is predictive of obstructive coronary artery disease (CAD), it is often used to risk stratify acute chest pain patients. We sought to further evaluate the clinical utility of the DF model within a chest pain evaluation center (CPEC).

Methods-Consecutive patients with chest pain and no known CAD or evidence of active ischemia were asked to participate in a prospective registry. Patients were classified based on cardiovascular risk factors, age, and DF classification. We compared data from the ED course, Duke Activity Status Index (DASI) and Seattle Angina Questionnaire (SAQ), hospitalization rates, and results of testing between patients with typical angina versus all others. Multivariate logistic regression was also used to assess for predictors of CAD by CTCA or positive ETT.
\end{abstract}

Results-Among 209 patients, 163 had atypical/noncardiac and 46 had typical chest pain. The SAQ and DASI scores were lower in the typical chest pain group (indicating more severe impairment), which were not statistically significantly different. There were no significant differences in risk factors or the results of CTCA, ETT, or cardiac catheterization. In the regression analysis, SAQ score, DASI score, and DF classification were not predictive of CAD by CTCA. Worsening angina frequency scores on the SAQ were marginally associated with positive ETT (OR 1.04, p=.04).

Conclusion-In a contemporary low-risk acute chest pain population, typical angina, as defined by the DF classification was not predictive of CAD or useful for identifying patients with higher symptom burden.

\section{Keywords}

Chest pain; Diamond Forrester; Duke Activity Status Index; Seattle Angina Questionnaire

Corresponding Author: David E. Winchester, MD, University of Florida College of Medicine, 1600 SW Archer Road PO Box 100277, Gainesville, FL 32610, Fax: 352846 0314, Telephone: 352273 9076, ; Email: David.Winchester@ medicine.ufl.edu.

Data were presented at the American College of Cardiology meeting, March 2015, San Diego, CA

Conflict of Interest: none declared 


\section{Introduction}

Chest pain is an exceedingly common presenting symptom in the emergency department (ED). In order to risk stratify patients presenting with acute chest pain, multiple standardized tools have been developed, including the GRACE, TIMI, and HEART risk models. ${ }^{1-3}$ These strategies are good for identifying high risk patients, but the management of low to intermediate risk patients remains controversial. Furthermore, while the negative predictive values of these tools may be useful for ruling out ACS, their positive predictive value is poor and can result in unnecessary admissions. Many institutions have created chest pain observation units, in which patients undergo extended observation with laboratory testing, serial electrocardiograms, and some form of ischemic testing for coronary artery disease (CAD).

For the past 30 years, the Diamond Forrester classification (DF) has been used to estimate the pretest probability of coronary artery disease in patients with chest pain and been validated prospectively in numerous trials. ${ }^{4-6}$. The DF was developed in an outpatient setting and has not been well studied in acute chest pain observation center (CPEC) patients. ${ }^{7}$ A notable advantage of the DF model is its simplicity, using only age, gender, and chest pain details to estimate the likelihood of obstructive CAD, which could represent a low-cost alternative for further risk-stratifying low-risk patients.

To better define the utility of the DF classification system in low-risk acute chest pain patients, we applied it to a sample of patients from a single CPEC. We hypothesized that patients with symptoms typical of angina, based on the DF assessment, would be more likely to have a positive test for $\mathrm{CAD}$ than patients with less typical symptoms.

\section{Methods}

At our facility, patients with low to intermediate $\mathrm{CV}$ risk are evaluated in a CPEC. The design of this physical unit and an example of the triage decision tool used to stratify risk has been previously described. ${ }^{8}$ In brief, patients presenting to the ED with chest pain are immediately triaged to a bed in the main ED where they receive an ECG and point of care troponin. Patients having ischemic ECG changes, positive cardiac biomarkers, hemodynamic instability, or a history of CAD are not referred to the CPEC. Those included in the CPEC are then evaluated for potential CAD.

The CPEC is staffed by a physician assistant or nurse practitioner trained in the assessment of chest pain and supervised by an ED physician. The decision on further clinical testing is based on a custom decision support tool, with decision making based on patients' perceived risk. The two primary testing modalities were exercise treadmill testing (ETT) and computed tomography coronary angiography (CTCA).

All consecutive patients in our CPEC were asked to participate in a prospective registry. As part of inclusion in the registry, patients were self-administered standardized, validated clinical instruments including the Duke Activity Status Index (DASI) and Seattle Angina Questionnaire (SAQ). The DASI is a 12-item questionnaire used to measure patient functional capacity, in which each item represents an activity of daily living weighted for its 
known metabolic equivalent. Scores range from zero to 58.2, with higher numbers representing better functional capacity. ${ }^{9}$ The SAQ measures quality of life in patients with angina and is measured across 5 different scales: angina severity, angina frequency, physical limitation, treatment satisfaction, and quality of life. Higher scores represent better quality of life and lower symptom burden. ${ }^{10}$ The treatment satisfaction scale was not included in this study as patients had not yet been treated at the time of the survey. Data on patient demographics, symptoms, medications, risk factors, comorbidities, and results of testing and CPEC course were recorded in a central database using REDcap software. ${ }^{11}$

All subjects in the CPEC registry provided written documentation of informed consent and our research protocol was approved by our Institutional Review Board. Using Diamond and Forrester's criteria, we created two cohorts of patients: those with typical angina symptoms, and those with atypical or noncardiac symptoms. Between these groups, we compared data from the ED course, DASI and SAQ scores, hospitalization rates, and results of testing between patients with typical angina versus all others.

All ETTs were interpreted by an attending physician using standard criteria for ischemia: horizontal or downsloping ST depression $\geq 1 \mathrm{~mm}$ in contiguous leads, exercise induced hypotension, or ventricular arrhythmias. Results of each ETT were used to calculate a Duke treadmill score. ${ }^{12}$ CTCA was performed on an Aquilion One CT scanner (Toshiba, Tustin, California) with 320 detectors and images reviewed on a Vital workstation (Vitrea, Minnetonka, Minnesota) by an interdisciplinary team of trained radiologists and cardiologists. Results were classified as normal if the calcium score was zero and there were no coronary lesions, nonobstructive if all lesions were $\mathbf{5 0 \%}$, or obstructive if at least 1 lesion was $250 \%$.

The primary outcome of our analysis was to compare the rate of positive CAD testing between the two cohorts. Multivariate logistic regression using a forward conditional method was also used to assess for predictors of CAD by CTCA and positive ETT. Proportions were compared by the chi-square test and continuous data by the Student's $t$ test. Statistical analyses were performed using SPSS, version 21 (IBM, Armonk, New York).

\section{Results}

A total of 209 low to intermediate risk patients were included in the study, with 163 classified as having atypical or noncardiac chest pain and 46 as having typical chest pain. Demographic information is shown in table 1 . Subjects were predominantly female and middle-aged in both groups. Patients with typical angina by DF classification were more likely to have had a prior stroke ( $3.2 \%$ vs. $0.6 \%, \mathrm{p}=0.03)$, hyperlipidemia ( $32.6 \%$ vs. $14.1 \%$, $\mathrm{p}=0.004)$, and to be treated with a statin $(13 \%$ vs. $4.9 \%, \mathrm{p}=0.05)$.

Clinical characteristics of patients stratified by DF classification are shown in Table 2 . The DASI score and SAQ scores across four scales were lower in the typical chest pain group (indicating more severe impairment), but the difference was not statistically significant (see Figure 1). For the primary outcome analysis, there were no statistically significant 
differences in the presence of CAD by CTCA or coronary angiography or in positive ETTs between patients with typical angina versus all others.

In the logistic regression analysis, SAQ score, DASI score, and DF classification were not predictive of CAD by catheterization or CTCA. Worsening angina frequency score on the SAQ was marginally associated with a positive ETT $(\mathrm{OR}=1.04, \mathrm{p}=.04)$.

\section{Discussion}

In this single center observational cohort study of low risk acute chest pain patients, symptoms typical of angina were not associated with detection of obstructive CAD. The clinical relevance of this finding is that in populations such as the one studied, symptoms alone may not be suitable for making decisions about who should undergo further testing for CAD.

Other contemporary studies of low risk acute chest pain patients have demonstrated similarly low diagnostic yield. ${ }^{13-15}$ The resulting challenge is that both clinicians and researchers have attempted to develop strategies that accurately identify patients at acceptably low risk to facilitate safe discharge from the ED. An approach that has demonstrated favorable results is the HEART score. This risk score consists of five clinical elements: history (i.e. symptoms), electrocardiogram, age, risk factors, and troponin. ${ }^{3} \mathrm{~A}$ score of $<4$ using this system is associated with a less than $2 \%$ risk of adverse cardiac events within 6 weeks of discharge. ${ }^{16}$

When applying the HEART score, clinicians are asked to rate the patients symptoms as slightly suspicious ( 0 points), moderately suspicious ( 1 point), or highly suspicious ( 2 points). The lack of precision for this component of the score makes some clinicians wary to apply it. Furthermore, the HEART score has been adapted as a means of identifying risk of ACS downstream and not at the time of presentation. The DF system has not yet been applied within the HEART scoring system, but may be a viable option for a future prospective trial.

Ongoing arguments exist about how to manage these low risk patients. In the United Kingdom, the National Institute for Health and Care Excellence (NICE) published guidelines to assess patients with chest pain of recent onset. ${ }^{17}$ Patients at low risk for CAD, which includes those with noncardiac chest pain by DF, are not advised to undergo further cardiac testing. In a retrospective study by Patterson et al. of patients presenting to chest pain centers, they found that $10 \%$ of patients who would have been excluded from further testing by the NICE guidelines went on to have significant CAD within 6 months. ${ }^{18}$ Thus, despite the low event rate relating to noninvasive testing in chest pain units, ongoing research aimed at properly risk stratifying these patients is critical.

Despite reporting exertional symptoms, the patients in our typical angina cohort had neither lower self-reported exercise tolerance (DASI) nor lower quality of life (SAQ) compared to the remainder of patients. The lack of differences with neither DASI nor SAQ retained in our regression model suggests that these instruments may not be clinically applicable in the low risk acute chest pain population. 


\section{Limitations}

Not all patients in our investigation underwent definitive angiography, and thus obstructive CAD may have been underdetected. The overall detection of CAD was low and sample size relatively small and as such, our study was inadequately powered to detect small differences between our symptom-based cohorts. Our institution applied a custom protocol to select patients for our observation unit, and thus results may not be generalizable to that of other chest pain units.

\section{Conclusion}

In a contemporary low-risk acute chest pain population, typical angina, as defined by the DF classification was not predictive of CAD or useful for identifying patients with higher burden of symptoms. DASI and SAQ scores were similarly not predictive of CAD. These tools appear to have limited utility in this selected population at low likelihood of CAD.

\section{Acknowledgments}

Funding: Supported by the Gatorade Trust through funds distributed by the University of Florida, Department of Medicine. Data collection was supported in part by the Clinical and Translational Science Institute (NIH Grants UL1TRR029890; UL1TR000064).

\section{References}

1. Fox KA, Dabbous OH, Goldberg RJ, Pieper KS, Eagle KA, Van de Werf F, Avezum A, Goodman SG, Flather MD, Anderson FA Jr, Granger CB. Prediction of risk of death and myocardial infarction in the six months after presentation with acute coronary syndrome: prospective multinational observational study (GRACE). BMJ. 2006; 333:1091. [PubMed: 17032691]

2. Antman EM, Cohen M, Bernink PJ, McCabe CH, Horacek T, Papuchis G, Mautner B, Corbalan R, Radley D, Braunwald E. The TIMI risk score for unstable angina/non-ST elevation MI: A method for prognostication and therapeutic decision making. JAMA. 2000; 284:835-842. [PubMed: 10938172]

3. Six AJ, Backus BE, Kelder JC. Chest pain in the emergency room: value of the HEART score. Neth Heart J. 2008; 16:191-196. [PubMed: 18665203]

4. Pryor DB, Harrell FE, Lee KL, Califf RM, Rosati RA. Estimating the likelihood of significant coronary artery disease. Am J Med. 1983; 75:771-780. [PubMed: 6638047]

5. Sox HC, Hickam DH, Marton KI, Moses L, Skeff KM, Sox CH, Neal EA. Using the patient's history to estimate the probability of coronary artery disease: a comparison of primary care and referral practices. Am J Med. 1990; 89:7-14. [PubMed: 2242131]

6. Pryor DB, Shaw L, McCants CB, Lee KL, Mark DB, Harrell FE Jr, Muhlbaier LH, Califf RM. Value of the history and physical in identifying patients at increased risk for coronary artery disease. Ann Intern Med. 1993; 118:81-90. [PubMed: 8416322]

7. Diamond GA, Forrester JS. Analysis of probability as an aid in the clinical diagnosis of coronaryartery disease. N Engl J Med. 1979; 300:1350-1358. [PubMed: 440357]

8. Winchester DE, Stomp D, Shifrin RY, Jois P. Design and implementation of a stand-alone chest pain evaluation center within an academic emergency department. Crit Pathw Cardiol. 2012; 11:123127. [PubMed: 22825532]

9. Hlatky MA, Boineau RE, Higginbotham MB, Lee KL, Mark DB, Califf RM, Cobb FR, Pryor DB. A brief self-administered questionnaire to determine functional capacity (the Duke Activity Status Index). Am J Cardiol. 1989; 64:651-654. [PubMed: 2782256] 
10. Spertus JA, Winder JA, Dewhurst TA, Deyo RA, Prodzinski J, McDonell M, Fihn SD. Development and evaluation of the Seattle Angina Questionnaire: a new functional status measure for coronary artery disease. J Am Coll Cardiol. 1995; 25:333-341. [PubMed: 7829785]

11. Harris PA, Taylor R, Thielke R, Payne J, Gonzalez N, Conde JG. Research electronic data capture (REDCap)-a metadata-driven methodology and workflow process for providing translational research informatics support. J Biomed Inform. 2009; 42:377-381. [PubMed: 18929686]

12. Mark DB, Shaw L, Harrell FE, Hlatky MA, Lee KL, Bengtson JR, McCants CB, Califf RM, Pryor DB. Prognostic value of a treadmill exercise score in outpatients with suspected coronary artery disease. N Engl J Med. 1991; 325:849-853. [PubMed: 1875969]

13. Hermann LK, Newman DH, Pleasant WA, Rojanasarntikul D, Lakoff D, Goldberg SA, Duvall WL, Henzlova MJ. Yield of routine provocative cardiac testing among patients in an emergency department-based chest pain unit. JAMA Intern Med. 2013; 173:1128-1133. [PubMed: 23689690]

14. Weinstock MB, Weingart S, Orth F, VanFossen D, Kaide C, Anderson J, Newman DH. Risk for clinically relevant adverse cardiac events in patients with chest pain at hospital admission. JAMA Intern Med. 2015; 175:1207-1212. [PubMed: 25985100]

15. Rovaj D, Neglia D, Lorenzoni V, Caselli C, Knuuti J, Underwood SR. Limitations of chest pain categorization models to predict coronary artery disease. Am J Cardiol. 2015; 116:504-507. [PubMed: 26081064]

16. Backus BE, Six AJ, Kelder JC, Bosschaert MA, Mast EG, Mosterd A, Veldkamp RF, Wardeh AJ, Tio R, Braam R, Monnink SH, van Tooren R, Mast TP, van den Akker F, Cramer MJ, Poldervaart JM, Hoes AW, Doevendans PA. A prospective validation of the HEART score for chest pain patients at the emergency department. Int J Cardiol. 2013; 168:2153-2158. [PubMed: 23465250]

17. National Institute for Health and Clinical Excellence. CG95. London: National Institute for Health and Clinical Excellence; 2010. Chest pain of recent onset: assessment and diagnosis of recent onset chest pain or discomfort of suspected cardiac origin.

18. Patterson CM, Nair A, Ahmed N, Bryan L, Bell D, Nicol ED. Clinical outcomes when applying NICE guidance for the investigation of recent-onset chest pain to a rapid-access chest pain clinic population. Heart. 2015; 101:113-118. [PubMed: 25217487]

Crit Pathw Cardiol. Author manuscript; available in PMC 2017 June 01. 


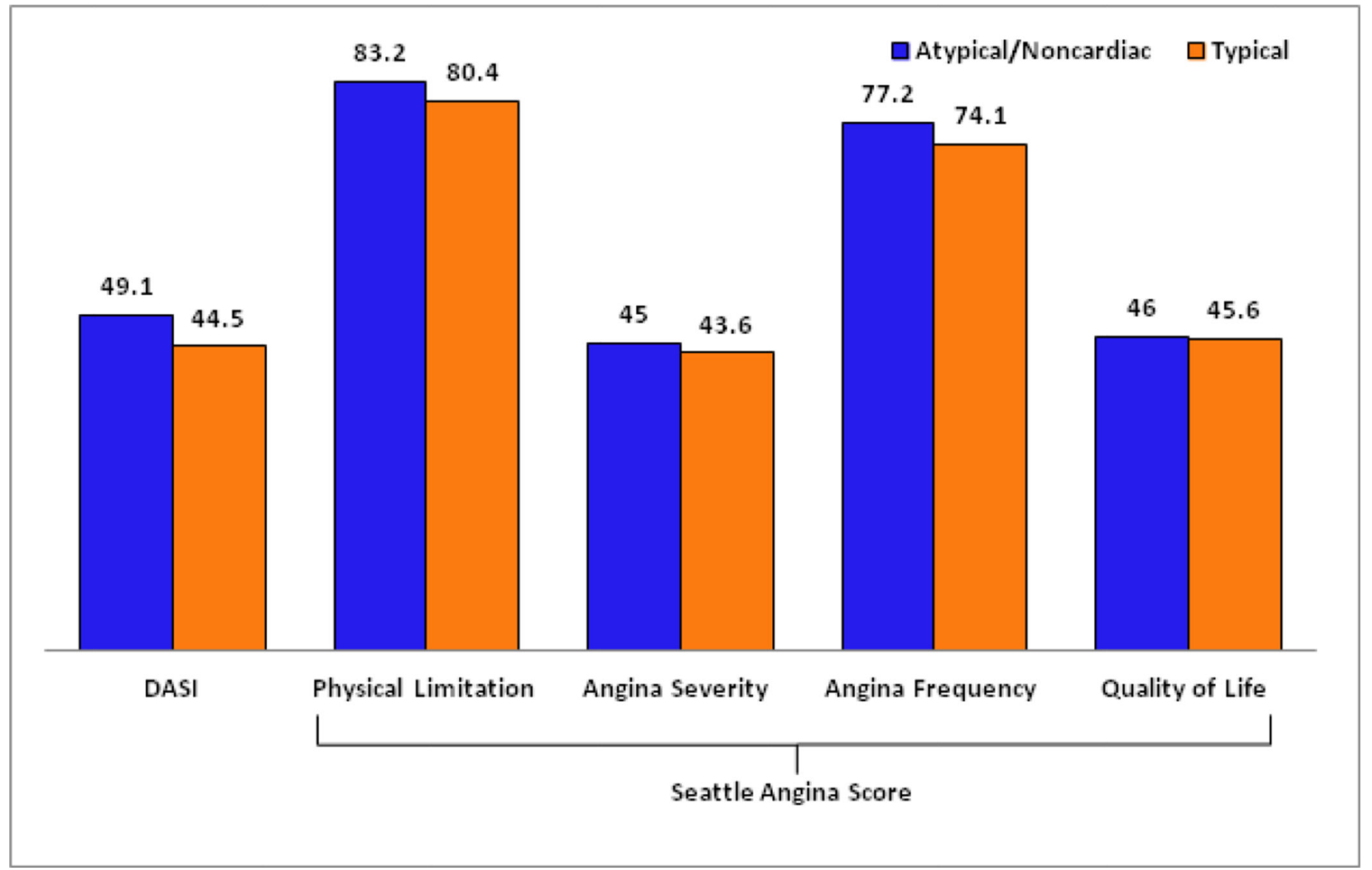

Figure 1. DASI score and Seattle Angina Scores by Diamond-Forrester Classification The mean DASI scores for atypical/noncardiac vs. typical chest pain patients are on the far left, followed by the four components of the Seattle Angina Questionnaire used in this study. 


\section{Table 1}

Baseline demographics by Diamond-Forrester classification

\begin{tabular}{|c|c|c|c|}
\hline & \multicolumn{2}{|c|}{ Diamond-Forrester Classification } & \multirow[b]{2}{*}{ p-value } \\
\hline & $\begin{array}{l}\text { Atypical/Non-cardiac } \\
(\mathrm{n}=163)\end{array}$ & $\begin{array}{l}\text { Typical } \\
(\mathrm{n}=46)\end{array}$ & \\
\hline Age - years & $45 \pm 9.9$ & $46 \pm 8.3$ & 0.55 \\
\hline Female & $103(63.2)$ & $32(69.6)$ & 0.43 \\
\hline Diabetes mellitus & $17(10.4)$ & $5(10.9)$ & 0.93 \\
\hline Hypertension & $60(36.8)$ & $19(41.3)$ & 0.58 \\
\hline Stroke & $1(0.6)$ & $3(6.5)$ & 0.03 \\
\hline Peripheral vascular disease & 0 & $1(2.2)$ & 0.22 \\
\hline Hyperlipidemia & $23(14.1)$ & $15(32.6)$ & 0.004 \\
\hline Tobacco use & $40(24.5)$ & $10(21.7)$ & 0.69 \\
\hline Family history of CAD & $76(46.6)$ & $27(58.7)$ & 0.15 \\
\hline GERD & $33(20.2)$ & $15(32.6)$ & 0.08 \\
\hline Depression & $31(19)$ & $10(21.7)$ & 0.68 \\
\hline Anxiety & $39(23.9)$ & $12(26.1)$ & 0.76 \\
\hline Chronic pain & $17(10.4)$ & $6(13)$ & 0.62 \\
\hline Aspirin & $9(5.5)$ & $5(10.9)$ & 0.20 \\
\hline Statin & $8(4.9)$ & $6(13)$ & 0.05 \\
\hline Beta blocker & $9(5.5)$ & $4(8.7)$ & 0.43 \\
\hline
\end{tabular}

All data expressed as no. (\%) or mean \pm standard deviation. 


\section{Table 2}

Characteristics of low-intermediate risk chest pain patients by Diamond-Forrester classification

\begin{tabular}{|c|c|c|c|}
\hline & \multicolumn{2}{|c|}{ Diamond-Forrester Classification } & \multirow[b]{2}{*}{ p-value } \\
\hline & $\begin{array}{l}\text { Atypical/Non-cardiac } \\
(n=163)\end{array}$ & Typical $(n=46)$ & \\
\hline DASI Score & $49.1 \pm 12.4$ & $44.5 \pm 17.2$ & 0.10 \\
\hline \multicolumn{4}{|l|}{ SAQ Scores } \\
\hline Physical Limitation & $83.2 \pm 21.3$ & $80.4 \pm 21.1$ & 0.45 \\
\hline Angina Stability & $45 \pm 37.7$ & $43.6 \pm 34.5$ & 0.83 \\
\hline Angina Frequency & $77.2 \pm 20.8$ & $74.1 \pm 26$ & 0.41 \\
\hline Quality of Life & $46 \pm 21.4$ & $45.6 \pm 25$ & 0.93 \\
\hline Number of episodes in previous week & $4 \pm 4.9$ & $4.6 \pm 11.4$ & 0.66 \\
\hline Severity & $6.7 \pm 2.4$ & $7 \pm 2.4$ & 0.55 \\
\hline Risk factors & $1.3 \pm 0.9$ & $1.7 \pm 1.3$ & \\
\hline Duke Treadmill Score & $6.8 \pm 4.1$ & $5.8 \pm 5.8$ & 0.51 \\
\hline Coronary Calcium Score & $41.9 \pm 108$ & $51.4 \pm 96.9$ & 0.75 \\
\hline Exercise Treadmill & $94(57.7)$ & $23(50)$ & 0.35 \\
\hline Cardiac CT angiography & $53(32.5)$ & $16(34.8)$ & 0.77 \\
\hline Admitted to the hospital & $12(7.4)$ & $3(6.5)$ & 0.85 \\
\hline Return visits to ED & $5(3.1)$ & 0 & 0.38 \\
\hline Obstructive CAD by CTCA & $5(3.1))$ & $1(2.2)$ & 0.74 \\
\hline Obstructive CAD by coronary angiography & $1(0.6)$ & $1(2.2)$ & 0.50 \\
\hline
\end{tabular}

All data expressed as no. (\%) or mean \pm standard deviation. 